\title{
Thousand per Square Millimeter
}

National Cancer Institute

\section{Source}

National Cancer Institute. Thousand per Square Millimeter. NCI Thesaurus. Code C67451.

A derived unit expressed as number of objects in thousands per unit of area equal to one millimeter. 